\title{
Projeto Pedagógico e as Mudanças na Educação Médica
}

\author{
Pedagogical Plan and New Approaches in \\ Brazilian Medical Schools
}

Ively Guimarães Abdalla'; Regina Celes de Rosa StellaII; Gianna Lepre Perim III; Rinaldo Henrique Aguilar-da-Silva ${ }^{I V}$; Jadete Barbosa Lampert ${ }^{V}$; Nilce Maria da Silva Campos Costa ${ }^{V *}$

\section{PALAVRAS-CHAVE: \\ - Educação Médica. \\ - Currículo. \\ - Avaliação de programas.}

\section{KEYWORDS:}

- Medical education.

- Curriculum.

- Program evaluation

Recebido em: 08/07/2008

Reencaminhado em: 20/12/2008

Aprovado em: 09/01/2009

REVISTA BRASILEIRA DE EDUCAÇ̃̃o MÉDICA $44 \frac{13(1 \text { supl. 1): 4.52:2009 }}{3}$

\section{RESUMO}

Este trabalho descreve os resultados do primeiro momento do projeto da Caem/Abem no eixo Projeto Pedagógico, um dos cinco eixos relevantes para avaliação das tendências de mudanças na escola médica. Analisa como os atores envolvidos com o curso de graduação percebem e situam a escola na sociedade ao estabelecerem sua missão política e pedagógica. Ao referir a tipologia do grupo de 28 escolas médicas, seguindo uma das três alternativas predominantes (tradicional, inovadora, avançada), esse eixo mostra a predominância de situação avançada, seguida da inovadora relativa aos vetores Perfil Biomédico e Epidemiológico-Social do profissional que pretende formar, e da aplicação da tecnologia. Quanto aos vetores da produção de conhecimentos, mostram dificuldades em produzir e ampliar as linhas de pesquisa para além das áreas biomédicas. Também mostram não ter facilidade para articular os cursos de graduação, pós-graduação e a educação permanente com vista às necessidades de saúde da população.

\section{ABSTRACT}

This paper describes the results of the first moment of the Caem/Abem project as refers to the axle Pedagogical Approach, one of the five axles relevant for evaluating the change trends in the medical school. It analyzes how the actors involved in the undergraduate course perceive and situate the school in the society by establishing its political and pedagogical mission. When classifying the group of 28 studied medical schools according to one of the three alternatives (traditional, innovative, advanced), this axle shows in the first place an advanced situation followed by innovative in the second place as refers to the vectors Biomedical and Socio-Epidemiological profile of the future professional and application of technology. With regard to the vectors focusing production of knowledge, the schools show difficulties in producing and extending the research lines beyond the biomedical areas. It also seems hard for them to articulate undergraduate and graduate courses and permanent education with view to the health needs of the population.
I Universidade Federal de São Paulo, São Paulo, Brasil.

"Universidade Federal de São Paulo, São Paulo, Brasil.

II Universidade Estadual de Londrina, Paraná, Brasil; Ministério do Esporte, Secretaria Nacional de Esporte Educacional. Distrito Federal, Brasil

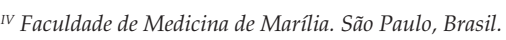

${ }^{v}$ Universidade Federal de Santa Maria, Rio Grande do Sul, Brasil..

${ }^{V I}$ Universidade Federal de Goiás, Goiás, Brasil.

"Os autores compõem a Comissão de Avaliação das Escolas Médicas da Associação Brasileira de Educação Médica (Abem). 


\section{INTRODUÇÃO}

O movimento transformador em saúde que ocorre em nosso país se reflete em diversas reformas que abarcam o sistema de assistência de saúde, no qual estão incluídos o cuidado primário em saúde e a formação de recursos humanos para atuar no sistema.

O cuidado primário em saúde, por parecer tratar-se de um serviço simples, usando geralmente poucos equipamentos, tem sido visto como assistência simplificada. No entanto, apresenta complexidade na articulação de diversos saberes e múltiplos profissionais. Isto irá se refletir na atuação do profissional médico, que precisa, a partir dessa nova concepção, desenvolver uma adequada abordagem e efetiva transformação nesse nível de atendimento, uma sofisticada síntese de saberes e complexa interação de ações: individuais e coletivas; curativas e preventivas; assistenciais e educativas ${ }^{1}$. A gama de demandas delimitada pela noção de necessidades básicas envolve um conjunto de ações médicas sanitárias e clínicas que resulta em um trabalho complexo, ao atender requisitos de alta capacidade resolutiva e, ao mesmo tempo, de alta sensibilidade diagnóstica, atuando corretamente nas demandas primárias e nos encaminhamentos dentro do sistema assistencial.

Após a homologação das Diretrizes Curriculares Nacionais (DCN) para os cursos de graduação de Medicina², pelo Ministério de Educação, em novembro de 2001, criou-se a necessidade de apoio e acompanhamento das implementações de mudanças nas escolas médicas brasileiras. A Associação Brasileira de Educação Médica (Abem), em sua vocação institucional, toma a iniciativa de promover a avaliação das tendências de mudanças nas escolas médicas ${ }^{3}$, tendo por objetivo impulsionar a construção de um processo avaliativo nessas instituições, que, além de diagnosticar o momento das escolas, permita auxiliar e acompanhar a evolução das mudanças de forma participativa e construtiva, sem perder de vista o objetivo de melhorar a qualidade da assistência prestada à saúde da população brasileira.

Nessa proposta da Abem, que visa à formação do médico no curso de graduação e ao atendimento das necessidades de saúde (NS), um dos eixos contemplados no projeto da Comissão de Avaliação das Escolas Médicas (Caem) ${ }^{4}$ da Abem é o eixo conceitual do Projeto Pedagógico (PP), referenciado no Projeto Pedagógico Institucional e Projeto de Desenvolvimento Institucional.

O PP é tratado neste estudo como um dos eixos relevantes na formação do médico, pois, segundo as diretrizes curriculares, o curso de Medicina deve ter como perfil do formando o médico com formação generalista, humanista, crítica e reflexiva, capacitado a atuar, pautado em princípios éticos, no pro- cesso de saúde-doença em seus diferentes níveis de atenção. Tendo em vista as ações de promoção, prevenção, recuperação e reabilitação à saúde, na perspectiva da integralidade da assistência, com senso de responsabilidade social e compromisso com a cidadania, como promotor da saúde integral do ser humano.

Este perfil de profissional só poderá ser desenvolvido no curso de Medicina na medida em que se dispuser de um projeto pedagógico estruturado de maneira a contemplar essas diretrizes que apontam para o modelo de médico com competências e habilidades preconizadas na atualidade. A escola deve proporcionar condições para formar profissionais que devem ser capazes de desenvolver um processo que possibilite identificar, promover e gerir os saberes através da mobilização de recursos que levem às competências profissionais requeridas ${ }^{5}$.

Isto gera o desafio de os cursos de Medicina formarem um profissional imbuído de uma prática ampliada com atuação "orientada por uma visão mais integrada, intersetorial, visando ampliar a estratégia de promoção, e pautada pela perspectiva da responsabilidade sanitária como elemento norteador das práticas em saúde" ${ }^{6}$.

Pode-se dizer que cumpre saber ensinar, auxiliar e orientar a construção de competências profissionais. Para desenvolvê-las, é preciso promover a integração do processo de ensino com o de produção de saúde em todos os níveis de atenção, o que faz com que se concorde com Schön ${ }^{7}$ quando afirma que a prática competente - na concepção atual - é mais que a prática profissional advinda exclusivamente do conhecimento sistemático, científico, tendo que resgatar o referencial artístico, pelo qual se aprende fazendo.

O desenvolvimento das competências necessárias à formação do médico formado por esse novo paradigma exige mais do que o saber sobre. Ser competente é saber sobre, saber fazer, saber ser e saber conviver, o que envolve não somente o domínio cognitivo, mas também o domínio psicomotor e afetivo.

Assim, para que se possa ensinar por competências, devem-se utilizar metodologias ativas de aprendizagem, orientadas para a autonomia, e o estabelecimento de uma relação de organicidade com o contexto da sociedade a que se aplica, conforme as proposições de Paulo Freire ${ }^{8}$ e outros educadores. Isto requer também o concurso de múltiplos saberes - saberes das disciplinas acadêmicas, saberes dos profissionais de serviço e saberes do indivíduo e da comunidade. Nesse processo de ensino-aprendizagem, mestre e estudante aprendem, e produzem conhecimento novo.

É necessário, então, que as escolas de Medicina estruturem seus projetos pedagógicos no sentido de se integrar aos 


\section{QUADRO 1}

Características predominantes nos currículos de graduação da escola de Medicina e outros cursos da saúde, na construção do paradigma da integralidade (inovador e avançado para atender às DNC) e do paradigma flexneriano (tradicional, conservador), no eixo Projeto Pedagógico

\begin{tabular}{|c|c|}
\hline \multicolumn{2}{|c|}{ DIRETRIZES CURRICULARES NACIONAIS } \\
\hline Modelo da Integralidade & Modelo Tradicional - Conservador \\
\hline \multicolumn{2}{|c|}{ PROJETO PEDAGÓGICO } \\
\hline $\begin{array}{l}\text { Enfatiza a importância dos fatores determinantes da saúde e orienta o curso } \\
\text { para as necessidades da Atenção Básica, com forte interação com os serviços } \\
\text { de saúde e a comunidade, articulando aspectos de promoção, prevenção, } \\
\text { cura e reabilitação }\end{array}$ & $\begin{array}{l}\text { Orienta o curso para os aspectos biomédicos, diagnóstico, } \\
\text { tratamento e recuperação do doente }\end{array}$ \\
\hline $\begin{array}{l}\text { Analisa de forma crítica e ampla a tecnologia e o custo-benefício da sua } \\
\text { aplicação, enfatizando a Atenção Básica de saúde }\end{array}$ & $\begin{array}{l}\text { Dá grande ênfase à aplicação da alta tecnologia na atenção } \\
\text { clínica e cirúrgica sem a análise crítica do custo-benefício }\end{array}$ \\
\hline $\begin{array}{l}\text { Na pesquisa, referencia-se nas necessidades de saúde com base } \\
\text { demográfica, epidemiológica e socioeconômica, no campo da Atenção } \\
\text { Básica, na gestão do sistema de saúde, na interação escola-serviço- } \\
\text { comunidade e no processo ensino-aprendizagem, e estimula a participação } \\
\text { dos discentes, contribuindo para a tomada de decisão com base em } \\
\text { informações relevantes com vistas à melhoria das práticas de assistência }\end{array}$ & $\begin{array}{l}\text { Na pesquisa, referencia-se nas necessidades de saúde com base } \\
\text { exclusivamente demográfica e epidemiológica com ênfase nas } \\
\text { ações diagnósticas e curativas }\end{array}$ \\
\hline $\begin{array}{l}\text { Oferece pós-graduação em campos gerais e especializados, articulada } \\
\text { com os gestores do Sistema de Saúde, visando às necessidades de saúde } \\
\text { quantitativas e qualitativas para a formação de médicos e franqueia a } \\
\text { educação permanente aos profissionais da rede }\end{array}$ & $\begin{array}{l}\text { Oferece residências, especializações, mestrado e doutorado em } \\
\text { campos especializados com total autonomia e não desenvolve } \\
\text { educação permanente }\end{array}$ \\
\hline
\end{tabular}

serviços de saúde, com o objetivo de formar profissionais aptos a responder às necessidades da população brasileira e à operacionalização do SUS.

Este trabalho integra o estudo feito pela Caem, que avalia as tendências de mudanças num grupo de escolas médicas brasileiras e tem como objetivo apresentar e analisar o eixo Projeto Pedagógico no curso de graduação em Medicina, o qual analisa como o curso se percebe e se situa na sociedade e como estabelece sua missão política e pedagógica.

A avaliação da Caem neste eixo conceitual é feita a partir de quatro vetores que possuem graduação em três níveis/alternativas de escolha9:

- Nível 1 - correspondente ao modelo tradicional;

- Nível 2 - correspondente ao modelo inovador;

- Nível 3 - correspondente ao modelo avançado.

O modelo de um projeto pedagógico avançado, que atenda às $\mathrm{DCN}$, requer uma referência padrão que sirva para que se alcance um mínimo de objetivos e metas, que possibilitem atingir a situação desejada. Este padrão deve ser delineado nos PP construídos pelas escolas, os quais devem atender ao modelo da integralidade preconizado na atualidade (Quadro 1) e se desdobrar nas ações que consolidam o programa didático-pedagógico, visto junto aos demais eixos.

\section{MÉTODO}

O instrumento de avaliação de tendências de mudanças das escolas médicas usado pela Caem foi respondido pelos atores sociais de cada escola: representantes docentes, discentes e técnico-administrativos. Cada vetor apresentou três níveis/situações alternativas (tradicional, inovadora e avançada). As escolas puderam classificar-se predominantemente em um dos três níveis. A tradicional correspondeu a características de um ensino tradicional, flexneriano; a inovadora apresenta inovações buscando adequar-se às mudanças; e a avançada apresenta características predominantemente de mudanças implantadas, que estão de acordo com as DCNs e buscam transformações. No mesmo exercício, a cada situação predominante são identificadas as justificativas e as evidências da alternativa escolhida. $\mathrm{O}$ instrumento, o método e a descrição dos vetores podem ser consultados no artigo Projeto de avaliação de tendências de mudanças no curso de graduação nas escolas médicas brasileiras (Lampert et al., p.5-18), disponível nesta revista.

Este trabalho apresenta os resultados do conjunto de 28 cursos de graduação no eixo Projeto Pedagógico, composto por quatro vetores: Biológico e Epidemiológico-Social; Aplicação Tecnológica; Produção de Conhecimentos; e Pós-Graduação e Educação Permanente. 


\section{GRÁFICO 1}

O eixo Projeto Pedagógico e tendências de mudanças num grupo de 28 escolas médicas brasileiras - Abem, 2007.

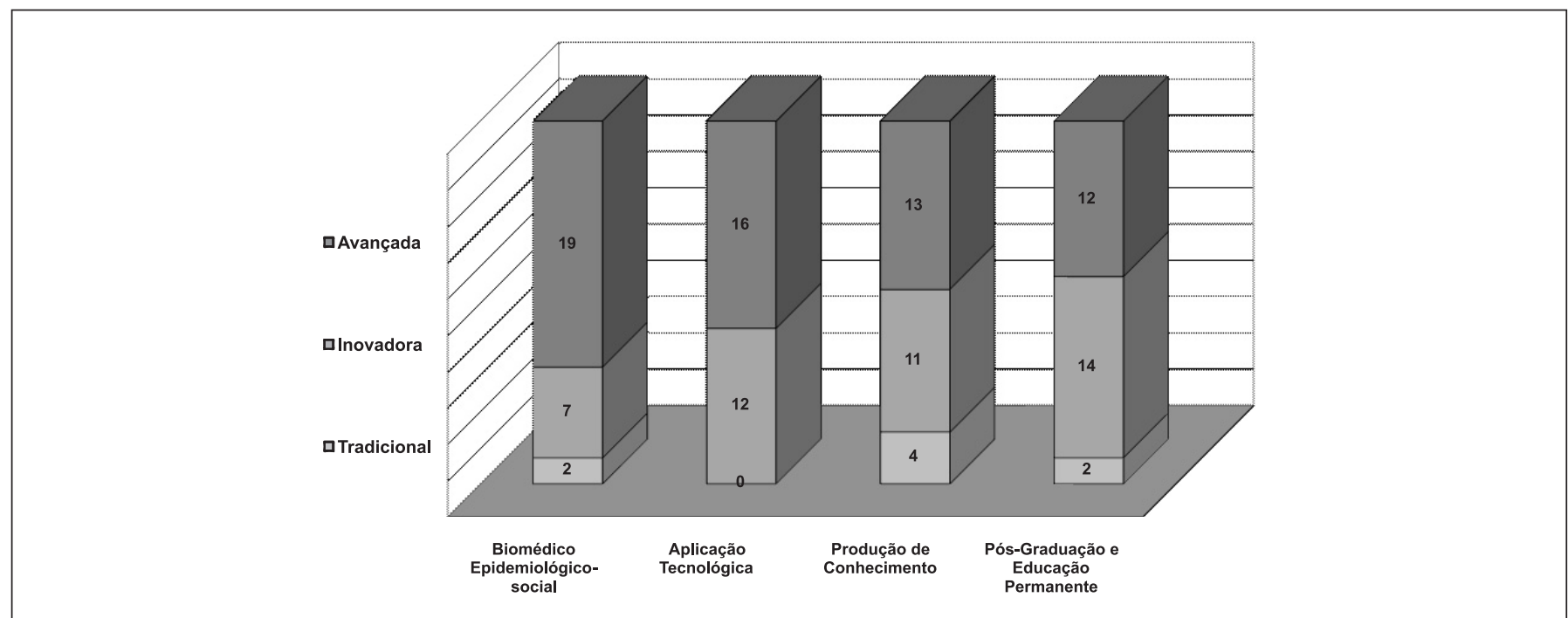

\section{RESULTADOS}

Os resultados apresentados no Quadro 2 e na Gráfico 1 demonstram a percepção dos atores sociais do grupo de 28 escolas médicas brasileiras quanto às tendências de mudança em relação ao eixo Projeto Pedagógico, e deste no contexto dos projetos pedagógicos. Além da classificação dos vetores, as escolas apresentam justificativas e evidências que indicam as fragilidades e as potencialidades que interferem no desenvolvimento do projeto pedagógico da escola.

A maioria das 28 escolas médicas que fizeram parte da análise apresentada neste trabalho se percebeu, no eixo Projeto Pedagógico, como avançadas e/ou inovadoras. Do grupo de 28 escolas médicas, 67,9\% escolhem a alternativa 3 (avançada). Enfatizam no PP a importância dos fatores determinantes da saúde e orientam o curso para as necessidades da Atenção Básica com forte interação com os serviços de saúde e a comunidade, articulando aspectos de promoção, prevenção, cura e reabilitação.

Neste eixo, o vetor Biomédico e Epidemiológico-Social analisa o quanto a escola aborda o processo saúde-doença voltado para as causas biológicas e epidemiológico-sociais, com participação da mesma no processo de desenvolvimento da saúde na região.

Verificamos que 2 escolas $(7,14 \%)$ orientam o curso para os aspectos biomédicos, diagnóstico, tratamento e recuperação do doente; 7 (25\%) orientam seu projeto no sentido de criar oportunidades de aprendizagem tendo em vista algum equilíbrio entre o biológico e o social seguindo orientação da prevenção primária, secundária e terciária (paradigma de Leavel \& Clark); e a maioria, 19 escolas $(67,86 \%)$, enfatiza a importância dos fatores determinantes da saúde e orienta o curso para as necessidades da Atenção Básica com forte interação com os serviços de saúde e a comunidade, articulando aspectos de promoção, prevenção, cura e reabilitação.

\section{QUADRO 2}

Tendências de mudanças no curso de graduação em 28 escolas médicas brasileiras ao considerarem os vetores do eixo Projeto Pedagógico e as alternativas/situações predominantes na percepção de cada escola - Abem, 2006

\begin{tabular}{|c|c|c|c|c|c|c|}
\hline VETORES & \multicolumn{2}{|c|}{$\begin{array}{c}\text { Alternativa } \\
1 \\
\text { tradicional }\end{array}$} & \multicolumn{2}{|c|}{$\begin{array}{c}\text { Alternativa } \\
2 \\
\text { inovadora }\end{array}$} & \multicolumn{2}{|c|}{$\begin{array}{c}\text { Alternativa } \\
3 \\
\text { avançada }\end{array}$} \\
\hline $\begin{array}{l}\text { Biomédico e } \\
\text { Epidemiológico- } \\
\text { Social }\end{array}$ & 2 & $7,14 \%$ & 7 & $25 \%$ & 19 & $67,86 \%$ \\
\hline $\begin{array}{l}\text { Aplicação } \\
\text { Tecnológica }\end{array}$ & - & - & 12 & $42,86 \%$ & 16 & $57,14 \%$ \\
\hline $\begin{array}{l}\text { Produção de } \\
\text { Conhecimentos }\end{array}$ & 4 & $14,29 \%$ & 11 & $39,29 \%$ & 13 & $46,42 \%$ \\
\hline $\begin{array}{l}\text { Pós-Graduação } \\
\text { e Educação } \\
\text { Permanente }\end{array}$ & 2 & $7,14 \%$ & 14 & $50 \%$ & 12 & $42,86 \%$ \\
\hline
\end{tabular}




\section{QUADRO 3}

Vetor Biomédico e Epidemiológico-Social com as justificativas e evidências apresentadas por 28 escolas médicas brasileiras ao se perceberem predominantemente numa das três alternativas (1 - tradicional, 2 - inovadora, 3 - avançada) ao considerarem como a escola orienta seu curso

\begin{tabular}{|c|c|c|}
\hline Alt. & Justificativas & Evidências \\
\hline \multirow[t]{2}{*}{1} & \multicolumn{2}{|c|}{ Orienta o curso para os aspectos biomédicos, diagnóstico, tratamento e recuperação do doente } \\
\hline & $\begin{array}{l}\text { Ensino com foco na doença e no doente } \\
\text { Currículo tradicional }\end{array}$ & $\begin{array}{l}\text { Currículo focado na doença e direcionado para tratamento e cura } \\
\text { Formação em hospital terciário }\end{array}$ \\
\hline \multirow[t]{2}{*}{2} & \multicolumn{2}{|c|}{$\begin{array}{l}\text { Orienta para criar oportunidades de aprendizagem, tendo em vista algum equilíbrio entre o biológico e o social seguindo orientação } \\
\text { da prevenção primária, secundária e terciária (paradigma de Leavel \& Clark) }\end{array}$} \\
\hline & $\begin{array}{l}\text { PP contempla o item, mas a prática se exercita pelo currículo } \\
\text { tradicional } \\
\text { Existência de algumas atividades e disciplinas nos três níveis } \\
\text { de atenção, porém sem integração } \\
\text { Alguns projetos de integração entre a escola e o município } \\
\text { Curso com avanços da primeira à quarta série, mas com } \\
\text { poucas mudanças no internato }\end{array}$ & $\begin{array}{l}\text { Resistência docente em exercer ABS } \\
\text { Aumento da participação do estudante na ABS } \\
\text { Inserção de profissionais da saúde da escola nos vários níveis de } \\
\text { atenção à saúde } \\
\text { PP e ementas de módulos temáticos } \\
\text { Atividades do internato centradas no curativo }\end{array}$ \\
\hline \multirow[t]{2}{*}{3} & \multicolumn{2}{|c|}{$\begin{array}{l}\text { Enfatiza a importância dos fatores determinantes da saúde e orienta o curso para as necessidades da Atenção Básica com forte } \\
\text { interação com os serviços de saúde e a comunidade, articulando aspectos de promoção, prevenção, cura e reabilitação }\end{array}$} \\
\hline & $\begin{array}{l}\text { PP e as práticas enfatizam os conteúdos biomédicos e } \\
\text { epidemiológicos sociais desde o início do curso, o que } \\
\text { possibilita reflexão dos fatores determinantes da saúde } \\
\text { Reconhecimento da necessidade de formação de } \\
\text { profissionais para o SUS } \\
\text { Curso fundamentado para a promoção da saúde }\end{array}$ & $\begin{array}{l}\text { Currículo integrado e orientado por competência profissional } \\
\text { Visitas domiciliares em diferentes níveis de atenção à saúde } \\
\text { Seleção de problemas de acordo com o perfil epidemiológico } \\
\text { Módulos que enfatizam a atenção à saúde } \\
\text { Aplicação de métodos ativos de ensino-aprendizagem } \\
\text { Orientação curricular e convênios nos níveis de atenção à saúde } \\
\text { Articulação com os serviços de saúde } \\
\text { PSF como eixo integrador do curso } \\
\text { Convênios com o município } \\
\text { Participação e representação nos Conselhos Municipais de Saúde } \\
\text { Ensino em ABS nos seis anos } \\
\text { Saúde coletiva ocorrendo em todo o currículo } \\
\text { Inserção nos três níveis de atenção à saúde }\end{array}$ \\
\hline
\end{tabular}

O vetor Aplicação Tecnológica trata da ênfase dada pela escola ao aplicar a alta tecnologia, desde usá-la na atenção clínica e cirúrgica, explicitá-la, quando usada em situações clínicas específicas, até analisá-la de forma ampla e crítica em relação às ocorrências, enfatizando as demandas nas necessidades de saúde da população.

Com relação à aplicação de tecnologia, 12 escolas (42,86\%) explicitam e analisam a tecnologia quando aplicada em situações clínicas específicas, e $16(57,14 \%)$ analisam de forma crítica e ampla a tecnologia, o custo-benefício da sua aplicação, enfatizando a Atenção Básica de saúde. Nenhuma das escolas dá grande ênfase à aplicação da alta tecnologia na atenção clínica e cirúrgica.

O vetor Produção de Conhecimentos verifica como as escolas desenvolvem e incentivam ou não, institucionalmente, a pesquisa. Os resultados mostram que 4 escolas (14,29\%) referenciam sua pesquisa pelas necessidades de saúde com base exclusivamente demográfica e epidemiológica, com ênfase nas ações curativas; 11 (32,29\%), além de desenvolverem pesquisa com base nas necessidades de saúde descritas, levam em conta aspectos socioeconômicos e estimulam pesquisa em Atenção Básica das comunidades. Aproximadamente 46\% 


\section{QUADRO 4}

Vetor Aplicação Tecnológica com as justificativas e evidências apresentadas por 28 escolas médicas brasileiras ao se perceberem nas diferentes alternativas (tradicional, inovadora e avançada)

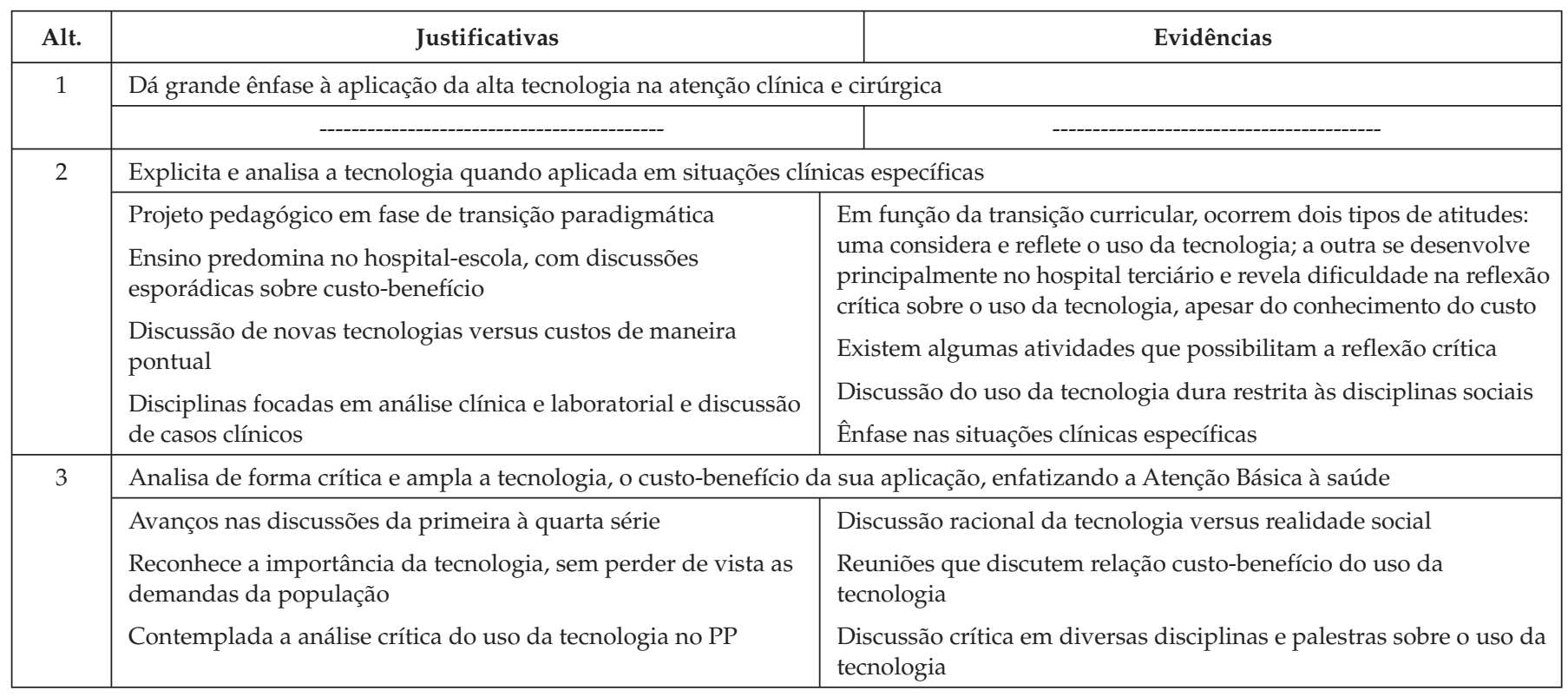

\section{QUADRO 5}

Vetor Produção de Conhecimento com justificativas e evidências na percepção de 28 escolas médicas brasileiras ao considerarem como a escola se referencia na pesquisa

\begin{tabular}{|c|c|c|}
\hline Alt. & Justificativas & Evidências \\
\hline \multirow[t]{4}{*}{1} & \multicolumn{2}{|c|}{$\begin{array}{l}\text { Na pesquisa referencia-se nas necessidades de saúde com base exclusivamente demográfica e epidemiológica com ênfase nas ações } \\
\text { curativas }\end{array}$} \\
\hline & Não existe política institucional para pesquisa & Orientadores do TCC são na maioria especialistas \\
\hline & Pouca pesquisa no curso & Grupos isolados de pesquisa \\
\hline & & Maioria das pesquisas desenvolvidas no hospital universitário \\
\hline \multirow[t]{5}{*}{2} & \multicolumn{2}{|c|}{$\begin{array}{l}\text { Na pesquisa referencia-se nas necessidades de saúde, incluindo, além da alternativa anterior, aspectos socioeconômicos, e envolve } \\
\text { discentes voluntários }\end{array}$} \\
\hline & \multirow{4}{*}{$\begin{array}{l}\text { Incentivo aos projetos de pesquisa (Pibic) e ligas (bolsas e } \\
\text { voluntários) } \\
\text { Movimento inicial de integração entre escola, serviço e } \\
\text { comunidade para desenvolvimento de pesquisa } \\
\text { Existência de estímulo à pesquisa em ABS }\end{array}$} & Projetos isolados de pesquisas, ligas e grupos de estudo \\
\hline & & Produção científica incipiente na área de epidemiologia \\
\hline & & Inexistência de recursos para desenvolvimento de pesquisas em ABS \\
\hline & & Trabalhos referenciados em NS \\
\hline \multirow[t]{8}{*}{3} & \multicolumn{2}{|c|}{$\begin{array}{l}\text { Na pesquisa referencia-se nas necessidades de saúde, incluindo além das anteriores, pesquisa no campo da Atenção Básica, da gestão } \\
\text { do sistema de saúde, interação escola-serviço-comunidade e processo ensino-aprendizagem, e estimula a participação dos discentes, } \\
\text { contribuindo para a tomada de decisão com base em informações relevantes com vistas à melhoria das práticas de assistência }\end{array}$} \\
\hline & \multirow{7}{*}{$\begin{array}{l}\text { Estruturação da pesquisa curricular na forma de eletivo; } \\
\text { fomento a bolsas } \\
\text { Pesquisa vinculada à NS regional } \\
\text { Mudanças curriculares influenciando as pesquisas em ABS } \\
\text { Reconhecimento da necessidade de produção de } \\
\text { conhecimento em ABS }\end{array}$} & Apoio para participação em congressos \\
\hline & & Aumento de participação discente em iniciação científica \\
\hline & & Aumento de produção nos programas stricto e lato sensu \\
\hline & & Mestrado em saúde coletiva com enfoque na ABS com participação de \\
\hline & & docentes e estudantes \\
\hline & & Linhas de pesquisa em saúde coletiva \\
\hline & & Projeto de extensão e pesquisa em ABS \\
\hline
\end{tabular}


QUADRO 6

Vetor Pós-Graduação e Educação permanente com justificativas e evidências na percepção de um grupo de 28 escolas médicas brasileiras

\begin{tabular}{|c|c|c|}
\hline Alt. & Justificativa & Evidências \\
\hline \multirow[t]{2}{*}{1} & \multicolumn{2}{|c|}{$\begin{array}{l}\text { Oferece residências, especializações, mestrado e doutorado em campos especializados com total autonomia e não desenvolve } \\
\text { educação permanente }\end{array}$} \\
\hline & Projeto pedagógico não contempla essa temática & Residências desenvolvidas em hospital universitário \\
\hline \multirow[t]{2}{*}{2} & \multicolumn{2}{|c|}{$\begin{array}{l}\text { Oferece alguma das modalidades anteriores em campos gerais e especializados e busca oferecer educação permanente relacionada } \\
\text { com o processo de trabalho }\end{array}$} \\
\hline & $\begin{array}{l}\text { Pouca oferta de cursos de educação permanente pelos } \\
\text { departamentos } \\
\text { Pesquisa em áreas específicas das especialidades } \\
\text { Reconhecem a importância da produção do conhecimento }\end{array}$ & $\begin{array}{l}\text { Educação permanente desenvolvida no eixo curricular da rede } \\
\text { Programa de residência e especialização em áreas gerais e curso de } \\
\text { extensão para os profissionais da rede e educação permanente de } \\
\text { egressos } \\
\text { Inexistência de recursos para o desenvolvimento de pesquisas }\end{array}$ \\
\hline 3 & $\begin{array}{l}\text { Políticas de incentivo institucional com oferta de mestrado, } \\
\text { apoio pedagógico e desenvolvimento de educação } \\
\text { continuada } \\
\text { Articulação com gestores municipais para desenvolvimento } \\
\text { de residência em PSF } \\
\text { Criação e implementação de curso de especialização em PSF, } \\
\text { adequação do profissional na integração ensino-serviço }\end{array}$ & $\begin{array}{l}\text { Mestrado em Saúde e Ambiente, ajuda de custo para pós-graduação } \\
\text { fora da instituição, bolsas para profissionais da área da saúde na pós- } \\
\text { graduação } \\
\text { Parceria com a SMS, residência multiprofissional em PSF } \\
\text { Especialização e residência em PSF, treinamento de médicos da rede } \\
\text { pública, seminários de especialistas }\end{array}$ \\
\hline
\end{tabular}

das escolas pesquisadas (13) possuem política institucional de produção de conhecimentos que contempla pesquisas em gestão do sistema de saúde, interação escola-serviço-comunidade e processo ensino-aprendizagem; incluem a participação discente e contribuem para a tomada de decisão com base em informações relevantes com vistas à melhoria das práticas de assistência e da gestão do sistema de saúde; além do aspecto técnico-operacional, também constroem propostas políticoinstitucionais e de avaliação de novas tecnologias.

No vetor Pós-Graduação e Educação Permanente, dois cursos $(7,14 \%)$ não desenvolvem educação permanente e oferecem pós-graduação em especialidades e/ou de maneira pontual, enquanto 14 escolas (50\%) buscam oferecer educação permanente, desenvolvem pós-graduação em campos gerais e se articulam com os gestores de saúde.

\section{DISCUSSÃO}

No vetor Biomédico e Epidemiológico-Social, a maioria das escolas $(92,86 \%)$ se percebe como inovadora ou avançada. Isto nos leva a afirmar que a quase totalidade delas, de acordo com o proposto no PP, orienta o curso para as necessidades da Atenção Básica com forte interação com os serviços de saúde e a comunidade, articulando aspectos de promoção, prevenção, cura e reabilitação, o que vai ao encontro do que preconizam as DCNs.

Quanto ao vetor de Aplicação Tecnológica, observa-se que nenhuma escola dá grande ênfase à tecnologia na aplicação clínica e cirúrgica, pois a maior parte analisa de forma ampla e crítica o custo-benefício da sua aplicação, enfatizando a Atenção Básica de saúde, o que faz com que se percebam como avançadas. Este aspecto deve estar favorecido pelo alto custo do uso das tecnologias instrumentalizadas com aparelhos sofisticados e pelo grande número de serviços prestados dentro dos planos de saúde e convênios.

Com relação ao vetor Produção de Conhecimento, a maior parte das escolas analisadas se percebe como tradicional ou inovadora e quase metade $(46,4 \%)$ desenvolve pesquisa voltada às necessidades de saúde, Atenção Básica, gestão em saúde, existência de fomento à bolsa de pesquisa.

No vetor Pós-Graduação e Educação Permanente, a maioria das respostas se concentra nas alternativas 1 e 2 . Isto sinaliza que em muitas das escolas ainda prevalece o modelo de pós-graduação voltado para residência, mestrado e doutorado em especialidades e educação permanente relacionada ao processo de trabalho. Ou seja, são cursos que se desenvolvem de forma independente, mesmo quando situados na mesma ins- 
tituição, fazem uso dos mesmos espaços e dispõem, inclusive, do mesmo corpo docente.

Ao se analisarem as justificativas e evidências apresentadas, observa-se que existem mais avanços na construção teórica do projeto pedagógico do que na operacionalização do mesmo. Isto porque, para que este se desenvolva na prática da escola em toda a sua plenitude, não basta apenas que ele atenda à dimensão pedagógica. É necessário também atender sua dimensão política, a qual traduz pensamento e ação, isto é, exprime a visão de mundo, de sociedade, de educação, do profissional e do estudante que a escola deseja ${ }^{10}$.

Dessa maneira, ao tomarem a decisão de mudar seu projeto pedagógico para atender as $\mathrm{DCN}$, as escolas médicas estão fazendo escolhas e desenvolvendo ações que são atos políticos, os quais, por sua natureza, dinâmica e histórica, serão seguidos de construções e desconstruções por parte da comunidade.

Ao (re)elaborar o PP, a escola estará em busca do conhecimento de sua realidade. Para que isso seja desenvolvido de forma que reflita o contexto em que a escola está inserida, é necessário que este seja construído coletivamente, para que as responsabilidades sejam compartilhadas de maneira que a escola alcance um desenvolvimento pleno em todos os aspectos: humano, cultural, político, institucional ${ }^{10}$.

Quando participa da construção do PP da escola, o coletivo o faz sob a perspectiva emancipatória, com a possibilidade de a inovação estar articulada no aspecto político-pedagógico, integrando o processo com o produto. Porque o resultado final é não só um processo consolidado de inovação metodológica, na esteira de um projeto construído, executado e avaliado coletivamente, mas um produto inovador que provocará também rupturas epistemológicas ${ }^{11}$.

Os resultados indicam que as transformações ocorridas nas escolas são mais evidenciadas nas concepções, o que é justificado pelos vetores que abordam o modelo que o PP segue (biomédico ou epidemiológico-social) e pela ênfase dada à aplicação de alta tecnologia.

Isto acontece com menor tendência na prática (desenvolvimento de pesquisa e integração dos cursos de formação - graduação, pós-graduação e educação permanente), o que parece se justificar pelo fato de algumas instituições ainda se apresentarem com idéias teóricas tradicionais, preocupandose mais com a transmissão do conhecimento do que com a produção deste e incentivando a participação discente.

\section{CONSIDERAÇÕES FINAIS}

As escolas médicas deste grupo se mostram avançadas para as transformações na construção dos projetos pedagógicos dos cursos de graduação.
Evidenciam tendências de mudanças para enfatizar a importância dos fatores determinantes da saúde e da doença e orientar o curso para as necessidades da Atenção Básica com forte interação com os serviços de saúde e a comunidade, articulando aspectos de promoção, prevenção, cura e reabilitação. E para analisar de forma crítica e ampla a tecnologia, o custo-benefício da sua aplicação, enfatizando a Atenção Básica de saúde.

Porém, quanto à produção de conhecimentos, mostram dificuldades em produzir e ampliar as linhas de pesquisa para além das áreas biomédicas. Também mostram não ter facilidade para articular os cursos de graduação, pós-graduação e a educação permanente, tendo em vista as necessidades contemporâneas de saúde, que, sendo múltiplas, exigem visão de demandas que, dinâmicas, requerem agilidade para soluções, num sistema que, em construção, deve dispor de mecanismos de referências e contrarreferências.

Estas dificuldades podem sinalizar que, apesar de concordarem com o modelo de uma formação médica voltada para a integralidade, preconizado nas diretrizes curriculares, na prática ainda se limitam ao desenvolvimento de atividades de produção de conhecimento insuficientes para descaracterizar o modelo tradicional. O estudo mostra que há um processo em construção, que parte de um modelo tradicional hegemônico de se fazer ciência na área da saúde para um modelo que se expande, introduzindo novas linhas de pesquisa, onde aparecem, entre outros, processo ensino-aprendizagem, processos avaliativos e de gestão.

\section{REFERÊNCIAS}

1. Schraiber LB, Nemes MIB, Gonçalves RBM. Saúde do Adulto: programas e ações na unidade básica. São Paulo: Hucitec; 1996. (Saúde em Debate. série didática, 3)

2. Brasil. Ministério da Educação. Conselho Nacional de Educação. Câmara de Educação Superior. Resolução CNE/CES $\mathrm{n}^{\mathrm{o}}$ 4, de 7 de novembro de 2001. Institui as Diretrizes Curriculares Nacionais do curso de graduação em Medicina.

3. Associação Brasileira de Educação Médica, Comissão de Avaliação das Escolas Médicas Brasileiras. Primeira fase do projeto de Avaliação das Tendências de Mudanças nas escolas médicas. [online]. [acesso em: 19 mar. 2008]. Disponível em: http:/ / www..org.br/primeirafase.htm.

4. Associação Brasileira de Educação Médica, Comissão de Avaliação das Escolas Médicas Brasileiras. Projeto de Avaliação e Acompanhamento das mudanças na escolas da área da saúde, 2007. [online]. [acesso em: 11 mar 2008]. Disponível em: http://www..org.br/pdf/projeto_ms.pdf.

5. Hissachi T, Aguilar-da-Silva RH. Currículo integrado por Competências Profissionais: reflexão sobre o trabalho de- 
senvolvido na Faculdade de Medicina de Marília (Famema). [online]. 2006 [acesso em: 2 fev. 2008]. Disponível em: www.gestaouniversitaria.com.br.

6. Oliveira GS, Koifman L. Integralidade do currículo de medicina: inovar/ transformar, um desafio para o processo de formação. In: Marins JJN, Rego S, Lampert JB, Araújo JGC de. (Org.). Educação médica em transformação: instrumentos para a construção de novas realidades. São Paulo: Hucitec; 2004.

7. Schön DA. Educando o profissional reflexivo: um novo design para o ensino e a aprendizagem. Porto Alegre: Artes Médicas Sul; 2000.

8. Freire P. Educação e atualidade brasileira. $2^{a}$ ed. São Paulo: Cortez; 2001.

9. Lampert JB. Tendência de Mudanças na Formação Médica no Brasil: tipologia das escolas. São Paulo: Hucitec; Rio de Janeiro: Abem; 2002.

10. Gonçalves GS de Q, Abdulmassih MBF. O Projeto político: algumas considerações. Revista Profissão Docente online [periódico na internete]. 2001 [acesso em: 25 mar.
2008];1(1). Disponível em: http://www.uniube.br/propep/mestrado/revista/vol01/01/.

11. Veiga IPA. Inovações e projeto político-pedagógico: uma relação regulatória ou emancipatória?. Cad. Cedes. [periódico na internet]. 2003 [acesso em 25 mar. 2008]; 23(6):267281. Disponível em http:/ / www.cedes.unicamp.br.

Apoio: Convênio n 1614/2007 - Fundo Nacional de Saúde/ MS.

\section{CONFLITOS DE INTERESSE}

Declarou não haver.

\section{ENDEREÇO PARA CORRESPONDÊNCIA}

Ively Guimarães Abdalla

Alameda dos Arapanés, 628 - apt $\mathrm{a}^{\mathrm{o}} 91$ - Moema

CEP: 04524-001 - São Paulo - SP

E-mail: ively.abdalla@unifesp.br 